\title{
Local Injection of Allogeneic Stem Cells from Apical Papilla Enhanced Periodontal Tissue Regeneration in Minipig Model of Periodontitis
}

\author{
Guoqing Li, ${ }^{1,2}$ Nannan Han,,3 Xiuli Zhang, ${ }^{1,3}$ Haoqing Yang, ${ }^{1}$ Yangyang Cao, \\ Songlin Wang $\mathbb{D}^{2,4}$ and Zhipeng Fan $\mathbb{D}^{1}$ \\ ${ }^{1}$ Laboratory of Molecular Signaling and Stem Cells Therapy, Beijing Key Laboratory of Tooth Regeneration and \\ Function Reconstruction, Capital Medical University School of Stomatology, No. 4 Tiantanxili, Dongcheng District, \\ Beijing 100050, China \\ ${ }^{2}$ Molecular Laboratory for Gene Therapy and Tooth Regeneration, Beijing Key Laboratory of Tooth Regeneration and \\ Function Reconstruction, Capital Medical University School of Stomatology, Beijing 100050, China \\ ${ }^{3}$ Department of Periodontology, Capital Medical University School of Stomatology, Beijing 100050, China \\ ${ }^{4}$ Department of Biochemistry and Molecular Biology, Capital Medical University School of Basic Medical Sciences, \\ No.10 Xitoutiao Youanmen, Fengtai District, Beijing 100069, China
}

Correspondence should be addressed to Songlin Wang; slwang@ccmu.edu.cn and Zhipeng Fan; zpfan@ccmu.edu.cn

Received 2 April 2018; Revised 3 June 2018; Accepted 21 June 2018; Published 12 July 2018

Academic Editor: Koichiro Wada

Copyright (C) 2018 Guoqing Li et al. This is an open access article distributed under the Creative Commons Attribution License, which permits unrestricted use, distribution, and reproduction in any medium, provided the original work is properly cited.

\begin{abstract}
Background. Discovering suitable seeding cells and simple application technique will be beneficial for MSC-mediated treatment of periodontitis. Stem cells from apical papilla (SCAPs) might be the candidate seeding cell for the periodontal tissues regeneration based on their origin and characters. In this research, we investigated the effect of SCAPs on periodontal tissue regeneration in swine by local injection. Methods. We established experimental periodontitis model in miniature pigs and then treated them with SCAPs by local injection. Clinical assessments, computed tomography (CT) scanning, histologic examination, and quantitative measurements were used to evaluate the effect of periodontal tissues regeneration. Results. At 12 weeks after injection, clinical assessments showed that probing depth, gingival recession, and attachment loss values were $5.44 \pm 0.77 \mathrm{~mm}$ versus $7.33 \pm 1.0 \mathrm{~mm}$ $(\mathrm{p}<0.01), 2.33 \pm 0.33 \mathrm{~mm}$ versus $2.11 \pm 0.69 \mathrm{~mm}$ ( $\mathrm{p}>0.05)$, and $7.78 \pm 0.84 \mathrm{~mm}$ versus $9.44 \pm 1.07 \mathrm{~mm}(\mathrm{p}<0.01)$ in SCAPs group and $0.9 \% \mathrm{NaCl}$ group, respectively. CT scan results showed a significant increase of $12.86 \mathrm{~mm}^{3}$ alveolar bone regeneration in SCAPs group compared with $0.9 \% \mathrm{NaCl}$ group. In addition, histopathology results demonstrated remarkable regeneration in SCAPs group, whereas regeneration of periodontal tissue was hardly found in $0.9 \% \mathrm{NaCl}$ group. Conclusion. Local injection of SCAPs could effectively restore tissue defects brought about by periodontitis in the swine model. Thus, SCAPs, as an easily accessible dentalderiving stem cell, may serve as an alternative application for periodontitis treatment.
\end{abstract}

\section{Introduction}

Periodontitis is a wide-spread chronic infectious disease that can destruct teeth supporting tissues, associates with many other diseases, and is the main cause of tooth loss of adults [1-5]. While the effects of restoring hard and soft periodontal tissues by conventional treatments remain unsatisfactory $[6,7]$. Thus far, appropriate methods are necessary for ideal regeneration of periodontal tissues. Recent years, cell-based therapy using mesenchymal stem cells (MSCs) is becoming a promising alternative strategy [8-12]. Previous studies focus on two types of MSCs on periodontal tissue regeneration including dental-derived MSCs such as PDLSCs (periodontal ligament stem cells), DPSCs (dental pulp stem cells), and non-dental-derived MSCs like BMSCs (bone marrow mesenchymal stem cells) [13-17]. They both have the potential to promote periodontal tissues regeneration, while dental tissue-derived MSCs have the peculiarities of their 
differentiation, proliferation, and immunosuppress capacities which may apply better effect on oral tissue regeneration. PDLSCs and DPSCs have been considered promising seed cells for periodontal tissue regeneration $[16,17]$. Comparison showed that PDLSCs and DPSCs expressed similar MSC markers with different levels. DPSCs had higher doubling rate and telomerase activity than PDLSCs $[18,19]$, while results of alkaline phosphatase (ALP) activity and mineralization studies suggested stronger osteogenic differentiation potential in PDLSCs than DPSCs [20, 21]. SCAPs are another kind of dental-derived MSCs from apical papilla of teeth with incompletely developed station, which is capable of selfrenewal and differentiating into different types of cells [22, 23]. Researchers have shown that SCAPs, which contribute to the formation of odontoblast-like cells, are capable of regenerate pulp-like tissue in emptied root canal space $[24,25]$. Also, higher proliferation, greater mineralization capacity and stronger osteogenic differentiation potential were found in SCAPs compared to that of PDLSCs and DPSCs, which makes SCAPs a candidate alternative seed cell for bone and dental tissue regeneration [24, 26-28].

Besides, previous researches on periodontal regeneration mainly relied on scaffold-based approaches, but problems such as host rejection, complication of transplantation, different degradation, and cell proliferation rate are the main concerns. Thus, non-scaffold tissue engineering strategy including cell injection and cell sheet has been of great interests to researchers these years. Cell sheet may be beneficial for stem cell-based tissue regeneration because of its mimicking cellular microenvironments and maintenance of endogenous extracellular matrix (ECM). However, periodontal flap operation was needed during cell sheet transplantation which is traumatic for patients. Cell injection has been used as therapy to many diseases and might also be a common approach to treat periodontitis. And the main superiority of cell injection is to provide a minimally invasive process. In our previous work, local injection of BMMSCs was used to treat periodontitis in rat and has good effect [8].

Nevertheless, study about SCAPs on periodontitis tissue regeneration is rarely found; we considered it a promising cell source by using the simple application technique on periodontitis treatment. In the present study, we aim to figure out whether SCAPs are a candidate seed cell for periodontal tissue regeneration by using the method of local injection. Periodontitis model was generated in minipigs and SCAPs were used by local application as the treatment. Clinical assessments, CT scans, and histopathology results showed that SCAPs were capable of serving as an appropriate alternative for periodontal regeneration.

\section{Material and Methods}

2.1. Cell Isolation and Culture. This study was approved by Ethical Committee of Beijing Stomatological Hospital (Review No. 2011-02) before the research started. Written informed consent was obtained from each patient before human impacted third molar with immature roots were collected under the guidelines of Beijing Stomatological Hospital, Capital Medical University. Wisdom teeth extracted from patients were stored in phosphate buffered saline (PBS) or serum-free cell culture medium immediately. Then $75 \%$ ethanol was used to disinfect the teeth and washed with PBS for several times. Apical papilla was separated gently from the tip of the root and cut into small pieces. Subsequently, the tissues were digested in a mix solution of $3 \mathrm{mg} / \mathrm{mL}$ collagenase type I (Worthington Biochemical Corp., Lakewood, NJ, USA) and $4 \mathrm{mg} / \mathrm{mL}$ dispase (Roche Diagnostics Corp., Indianapolis, IN, USA) for about $1 \mathrm{~h}$ at $37^{\circ} \mathrm{C}$ and then passed the digested tissues through a $70-\mu \mathrm{m}$ strainer (Falcon, BD Labware USA) to obtain isolated cell suspensions. SCAPs were grown in a humidified incubator under $5 \% \mathrm{CO}_{2}$ at $37^{\circ} \mathrm{C}$ in DMEM alpha modified Eagle's medium (Invitrogen, Carlsbad, CA, USA), supplemented with $15 \%$ fetal bovine serum (FBS; Invitrogen), 2mmol/l glutamine, $100 \mathrm{U} / \mathrm{ml}$ penicillin, and $100 \mu \mathrm{g} / \mathrm{ml}$ streptomycin (Invitrogen). The culture medium was changed every 3 days. SCAPs were identified $[29,30]$ and cells at passages 3-5 were used in subsequent experiments.

2.2. Animals. Six inbred male minipigs, 18 months old and weighing 55-60kg, were obtained from the Institute of Animal Science of the Chinese Agriculture University (Beijing, China) and were housed under conventional conditions, with free access to water and a regular supply of soft food diet. The study protocol was approved by the Animal Care and Use Committee of Capital Medical University. Prior to surgery, the minipigs were clinically assessed and then anesthetized with a combination of ketamine chloride $(6 \mathrm{mg} / \mathrm{kg})$ and xylazine $(0.6 \mathrm{mg} / \mathrm{kg})$.

2.3. MSC-Mediated Treatment for Swine Periodontitis. 12 periodontitis defects were generated in 6 minipigs. Defects with a size of $3 \mathrm{~mm}$ (width) $\times 5 \mathrm{~mm}$ (depth) $\times 7 \mathrm{~mm}$ (length) in the mesial region of the bilateral mandibular first molars were created by removing alveolar bone and cement with a 4-0 silk ligament sutured around the cervical portion after the operation. On the root surface, notch-shaped marks were made at the floor of the defects. Then the minipigs received injections at three sites surrounding each defect: the mesial, the distal, and the middle of the molar four weeks after surgery. Animals were randomly assigned to each group with split mouth method (6 minipigs for each group), injected with $0.9 \% \mathrm{NaCl}(0.9 \% \mathrm{NaCl}$ group) and SCAPs+ $0.9 \% \mathrm{NaCl}$ (SCAPs group). In each site around the defect, SCAPs with approximately $2 \times 10^{6}$ SCAPs in $0.2 \mathrm{ml} 0.9 \% \mathrm{NaCl}$ were injected subperiosteally with the needle entered from the mucosa straight to the surface of bone.

2.4. Clinical Assessments and CT Scanning of Periodontal Tissue Regeneration. Clinical assessments, including probing depth (PD), gingival recession (GR), and attachment loss (AL), were measured on each experimental tooth right before the generation of periodontitis models, before the treatment, and 12 weeks after transplantation. The regeneration of newborn bone was analyzed based on three-dimensional reconstructive CT scan (Siemens, Berlin, Germany) using Geomagic 12 by fitting three-dimensional reconstruction images at the indicated time points before the treatment and 


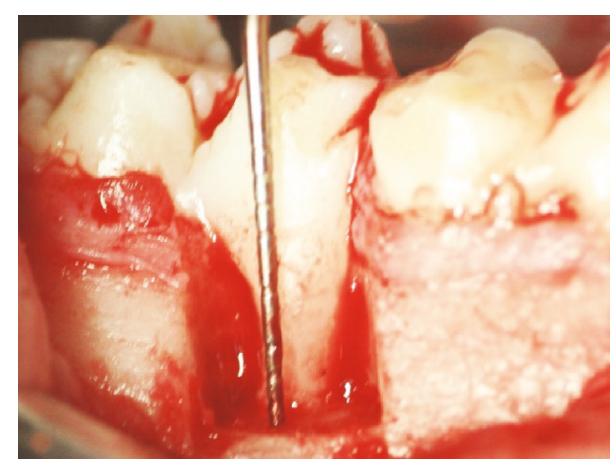

(a)

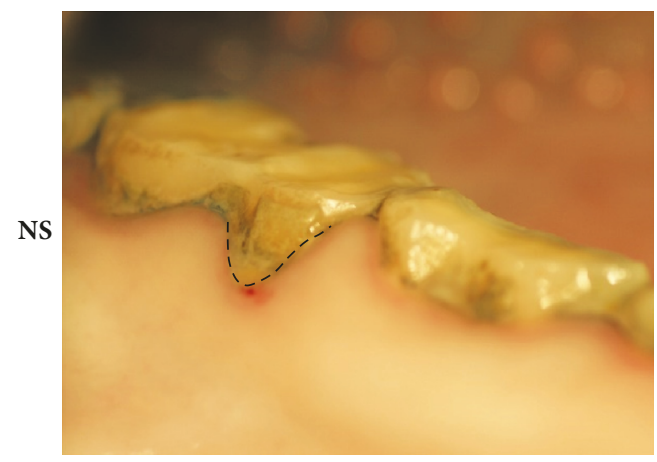

(c)

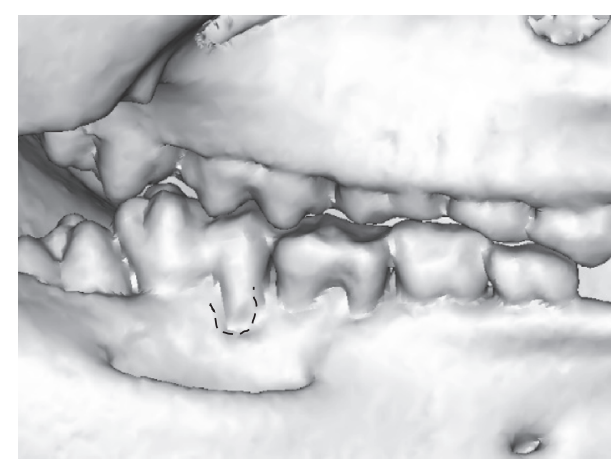

(b)

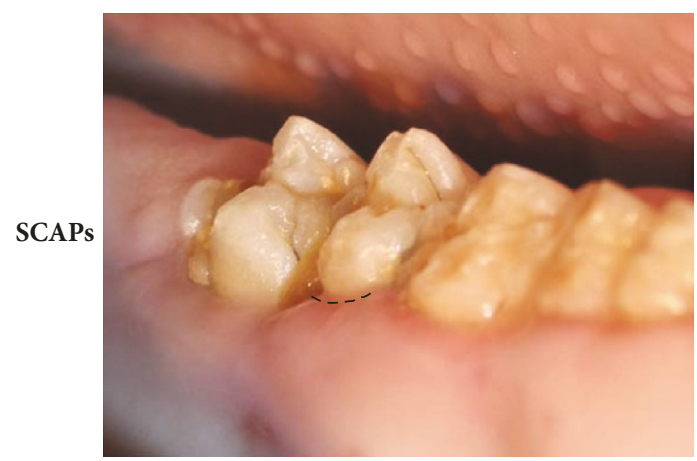

(d)

FIGURE 1: Local application of SCAPs for periodontitis treatment in a minipig periodontal model. (a-b) Bone defects of $3 \mathrm{~mm} \times 5 \mathrm{~mm} \times 7 \mathrm{~mm}$ were generated in the mesial region of the bilateral mandibular first molars (a). Three-dimensional CT images showed obvious bone defect in experimental region (b). (c-d) Intraoral manifestations demonstrating tissue regeneration in $0.9 \% \mathrm{NaCl}$ group (c) and SCAPs group 12 weeks after the treatment $(\mathrm{d})$.

12 weeks after transplantation; then a growth volume of newly regenerated tissue can be obtained and calculated. The CT scanning length was $0.62 \mathrm{~mm}$.

2.5. Histologic Assessments. 12 weeks after transplantation, samples were harvested, fixed with $4 \%$ formaldehyde (PFA, $\mathrm{PH}=7.4-7.6)$, decalcified with $10 \%$ ethylene diamine tetraacetic acid (EDTA, pH 7.4-7.6), and then embedded in paraffin. Sections $(5 \mu \mathrm{m})$ were stained with hematoxylin and eosin (H\&E). The volume of new cementum was analyzed using image-Pro $1.49 \mathrm{v}$ (National Institutes of Health, Bethesda, MD, USA).

2.6. Statistics. All statistical calculations were performed using SPSS10 statistical software. Student's $t$-test was utilized to determine statistical significance, with a $\mathrm{p}$ value of $\leq .05$ considered significant.

\section{Results}

3.1. Improved Gingival Status and Clinical Assessments in SCAPs Group Compared to 0.9\% $\mathrm{NaCl}$ Group. To investigate the effect of SCAPs for tissue regeneration, experimental periodontitis model was created in 6 minipigs with 12 defects (Figure 1(a)); CT scans showed successful model was established after 4 weeks (Figure 1(b)). 12 weeks after transplantation, intraoral photographs showed that gingival appearance is better in SCAPs group than that in $0.9 \% \mathrm{NaCl}$ group (Figures $1(\mathrm{c})$ and $1(\mathrm{~d})$ ).

Animals were then separated into two groups by split mouth method by injecting with SCAPs $+0.9 \% \mathrm{NaCl}$ or $0.9 \%$ $\mathrm{NaCl}$, respectively. 12 weeks after treatment, PD values were $7.33 \pm 1.0 \mathrm{~mm}$ in the $0.9 \% \mathrm{NaCl}$ group and $5.44 \pm 0.77 \mathrm{~mm}$ in the SCAPs group $(\mathrm{p}<0.01)$ (Figure $2(\mathrm{a})$ ). GR values were $2.11 \pm 0.69 \mathrm{~mm}$ in the $0.9 \% \mathrm{NaCl}$ group and $2.33 \pm 0.33 \mathrm{~mm}$ in the SCAPs group ( $\mathrm{p}>0.05)$, which had no significant difference (Figure 2(b)). As for AL, the values were $9.44 \pm 1.07 \mathrm{~mm}$ in the $0.9 \% \mathrm{NaCl}$ group and $7.78 \pm 0.84 \mathrm{~mm}$ in the SCAPs group $(\mathrm{p}<0.01)$ (Figure 2(c)).

These results revealed that injection of SCAPs can promote the recovery of gingival and led to improvement of PD and AL.

3.2. CT Scan Results Showed More Bone Regeneration after SCAPs Application. 12 weeks after treatment, three-dimensional reconstruction results showed much more alveolar bone regeneration in SCAPs group (Figures 3(a) and 3(b)). Computed tomography imaging showed higher alveolar in SCAPs group (Supplementary Fig1A, B). Quantitative analysis showed that the volume of newborn bone in the SCAPs group is $22.73 \pm 4.94 \mathrm{~mm}^{3}$ versus $9.87 \pm 3.53 \mathrm{~mm}^{3}$ in $0.9 \% \mathrm{NaCl}$ 

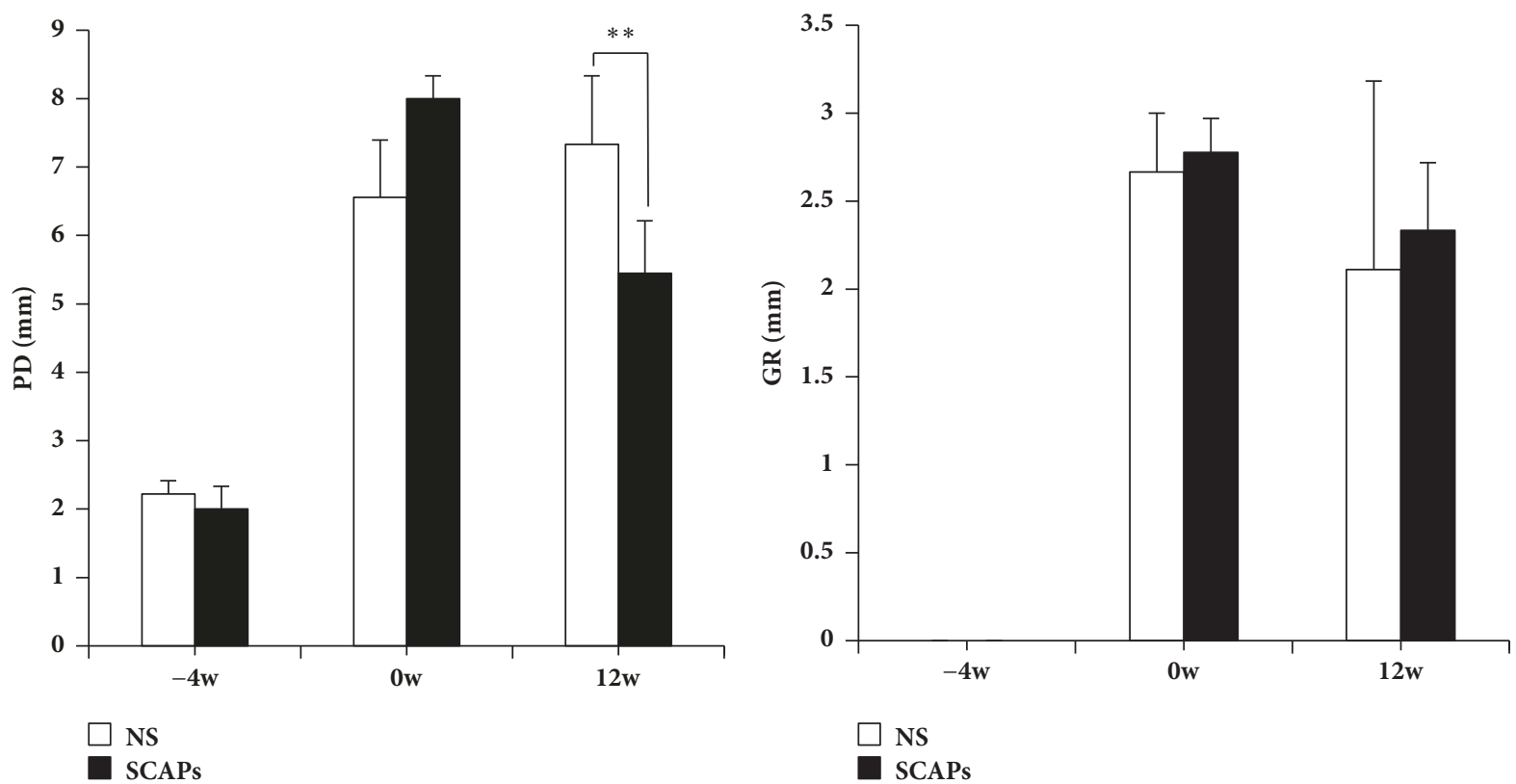

(a)

(b)

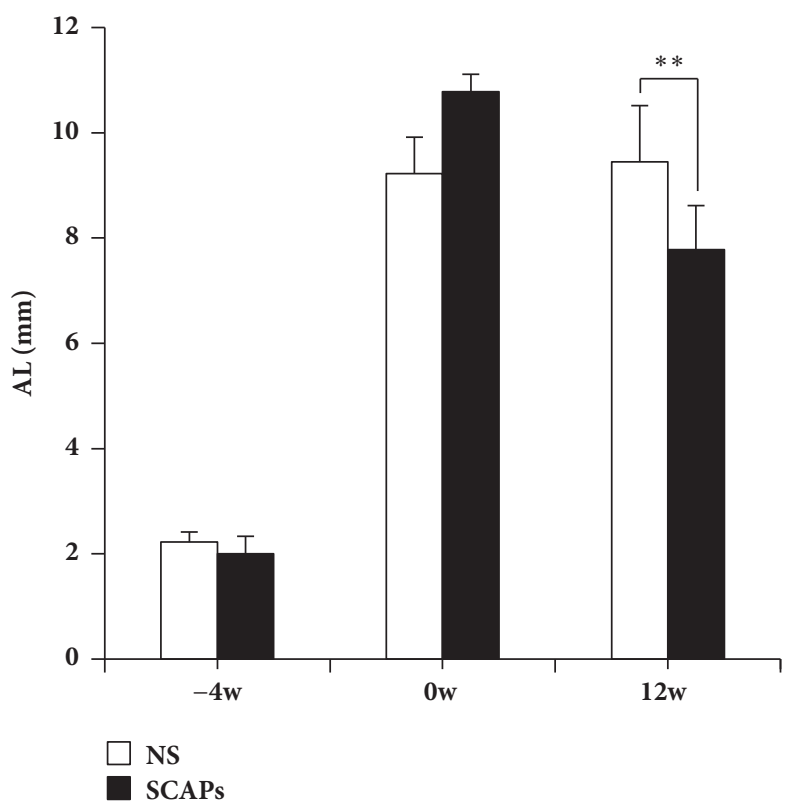

(c)

FIGURE 2: Clinical assessments of the periodontal situation. $(\mathrm{a}-\mathrm{c}) 12$ weeks after transplantation, the values of PD and AL were significantly improved in the SCAPs group compared to that of the $0.9 \% \mathrm{NaCl}$ group, while GR values had no significance. Bars and vertical lines: mean \pm standard deviation. Student's $t$-test was applied to test statistical significance. $* * \mathrm{p}<0.01$. PD, probing depth; AL, attachment loss; GR, gingival recession.

group (Figure 3(c), p<0.01), demonstrating that SCAPs enhanced bone formation in minipigs periodontitis defects model.

\subsection{Histopathologic Assessment Demonstrated That SCAPs} Enhanced Periodontal Tissues Regeneration. Histopathologic assessment showed that typical periodontitis features still existed in $0.9 \% \mathrm{NaCl}$ group, including deep periodontal pocket, abundant inflammatory cell infiltration in sulcular epithelium, and lack of periodontal ligament and the typical structure of Sharpey's fibers (Figures 4(a), 4(b), 4(e), and $4(\mathrm{~g}))$. In contrast, typical structure of Sharpey's fibers and a lot of periodontal ligament were regenerated in SCAPs group. Moreover, few inflammatory cells and newly formed Sharpey's fibers could also be observed in SCAPs group. There was thicker and more mature regenerated cementum in SCAPs group compared to that in $0.9 \% \mathrm{NaCl}$ group (Figures 4(c), 4(d), 4(f), and 4(h)). Although the length of new 


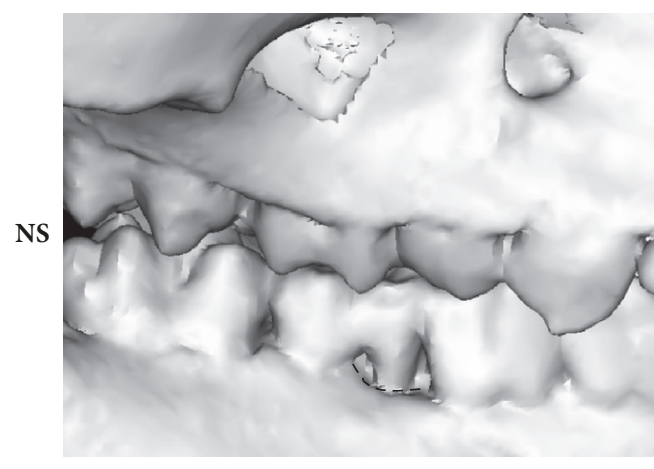

(a)

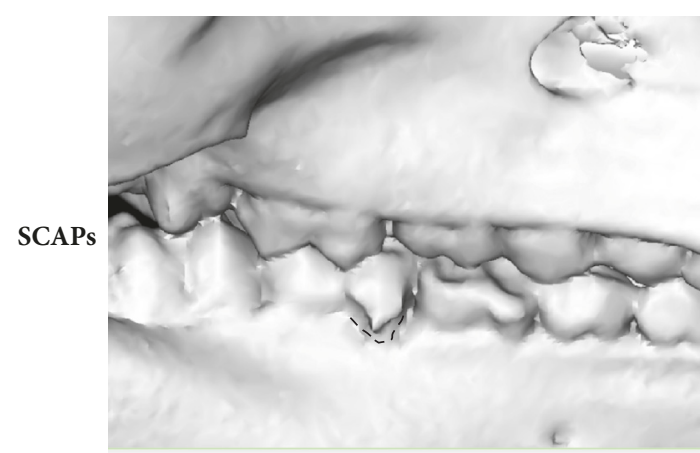

(b)

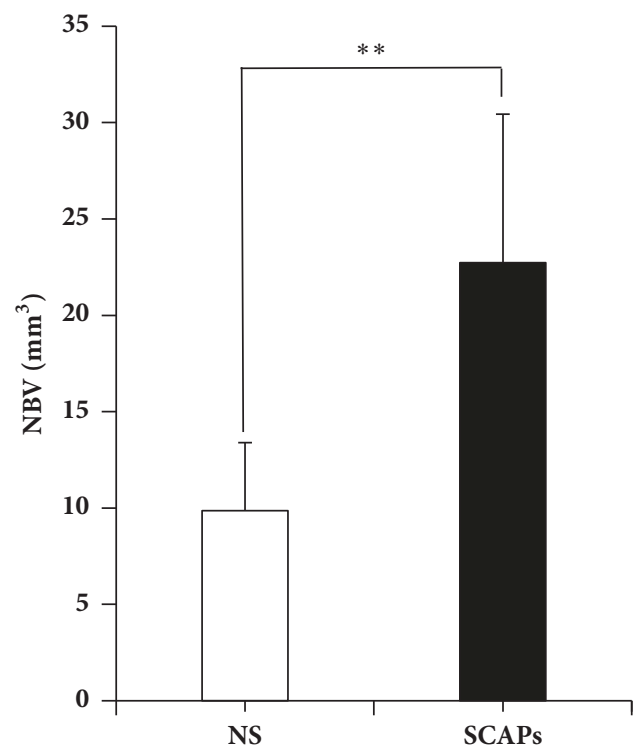

(c)

FIGURE 3: CT scan showed superior regenerative periodontal tissue in SCAPs group compared with 0.9\% NaCl group. (a, b) Three-dimensional CT images revealed limited bone formation in $0.9 \% \mathrm{NaCl}$ group 12 weeks after transplantation (a). SCAPs-mediated nearly complete alveolar bone regeneration (b). Analysis of CT results showed that the efficiency of newborn bone in the SCAPs group was significantly better than the $0.9 \% \mathrm{NaCl}$ group $(\mathrm{c})$. Student's $t$-test was performed to determine statistical significance $(* * \mathrm{p}<0.01)$.

generated cementum showed no difference (Figure 5(a)), the width is $91.4 \pm 7.9 \mu \mathrm{m}$ in $0.9 \% \mathrm{NaCl}$ group versus $158.1 \pm 16.3 \mu \mathrm{m}$ in the SCAPs group (Figure 5(b), $\mathrm{p}<0.01$ ), which indicated more new cementum regenerated in the SCAPs group.

\section{Discussion}

In this research, we investigated the effect of SCAPs-mediated therapy for periodontitis in minipigs. Periodontitis model was established in minipigs and local injection of SCAPs was used as the treatment. 12 weeks after the treatment, clinical assignment, CT scan, HE staining, and quantitative analysis demonstrated superior regenerative effect of periodontal tissue in SCAPs group, indicating that SCAPs, as a dental tissue-derived MSCs, might serve as suitable alternative cell source for periodontal tissue engineering.

Periodontitis leads to destruction of periodontal supported tissues such as alveolar bone, cementum, periodontal ligament, and gingiva. The purpose of treatment is to cease the periodontitis process, regenerate tissues, and restore periodontal function [28]. Researches showed MSCs-mediated therapy a promising treatment, in which appropriate seed cell is the key process, so broaden and better alternative of the cell source is still in great need.

Dental-derived MSCs based therapy for periodontitis has approved certain achievements. Both allogeneic and autologous PDLSCs are believed to have great therapeutic effect on regeneration of soft and hard periodontal tissues in animal models [16, 31], but the source of PDLSCs is limited. SCAPs can be obtained from unmatured extracted wisdom teeth. Apical papilla is the precursor of root, which is composed of cells with more undifferentiated ability than DPSCs and PDLSCs. SCAPs express MSCs markers and can differentiate into different cell types such as neural cells, adipocytes, odontogenic cells, and formatting vascularized pulp-like tissue in vivo $[22,32,33]$. On treatment of periodontitis, SCAPs showed their superiority compared with other MSCs such as non-dental-derived MSCs like BMMSCs and 

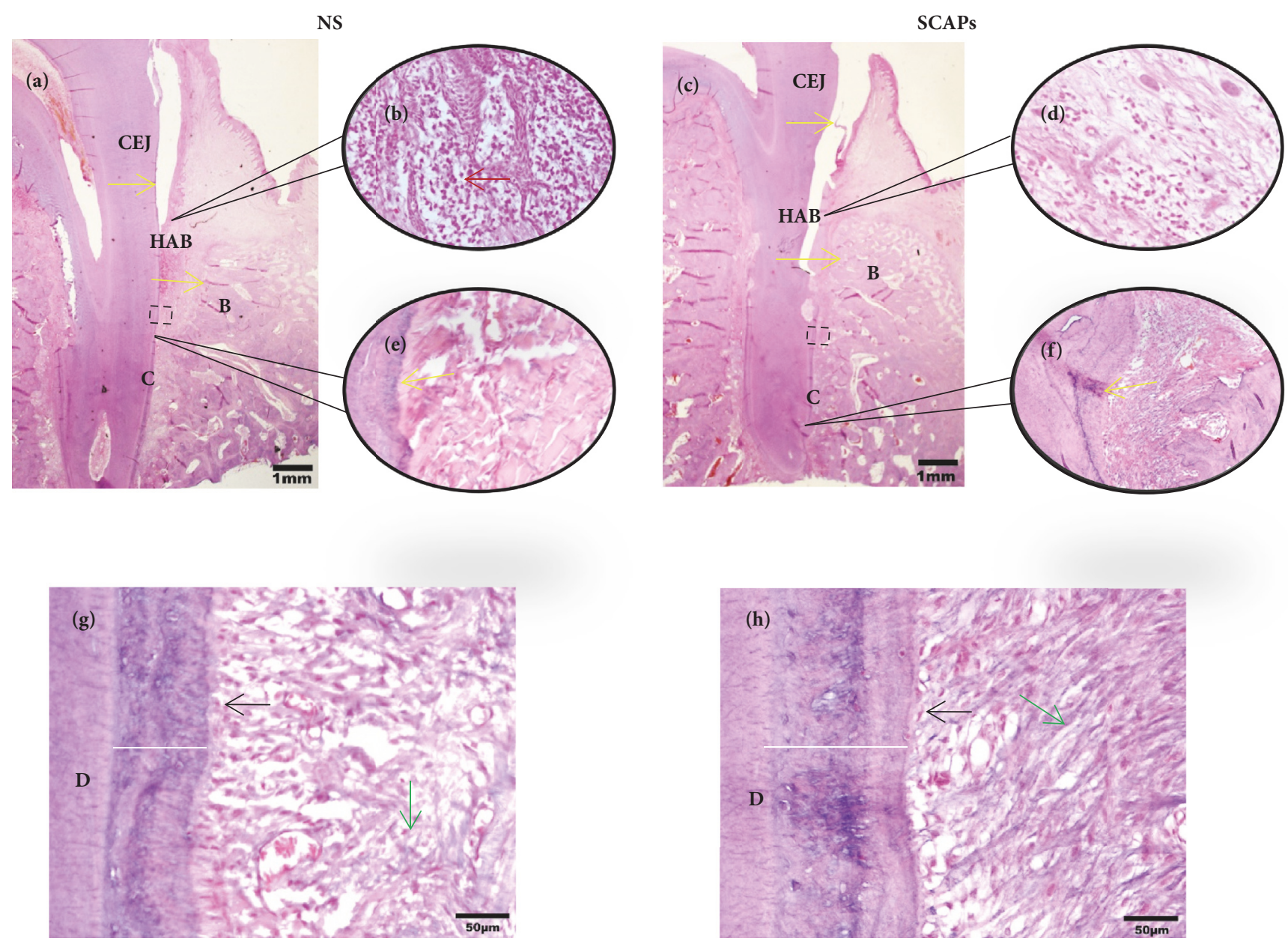

FIGURE 4: Whole view of histopathologic assessment for periodontal tissue regeneration by HE. HE staining showing new periodontal tissue regeneration in the periodontal defect area in $0.9 \% \mathrm{NaCl}$ group (a, b, e, and g) and SCAPs group ( $\mathrm{c}, \mathrm{d}, \mathrm{f}$, and h). (b) Enlarged view of sulcular epithelium of $0.9 \% \mathrm{NaCl}$ group; (d) enlarged view of sulcular epithelium of SCAPs group; (e) and (f) enlarged view shows notch-shaped marks (yellow arrow) made in $0.9 \% \mathrm{NaCl}$ group and SCAPs group. (g, h) Enlarged view of periodontal tissues in $0.9 \% \mathrm{NaCl}$ group and SCAPs group (black rectangular area in a and b). Red arrow, inflammatory cells; green arrow, Sharpey's fibers; black arrow, cementoblast; white bar, the width of new cementum. Bar: $=1 \mathrm{~mm}(\mathrm{a}, \mathrm{b}), 100 \mu \mathrm{m}(\mathrm{e}, \mathrm{f})$, and $50 \mu \mathrm{m}(\mathrm{g}, \mathrm{h}) . \mathrm{D}$, dentin; C, cementum; B, bone; CEJ, cemento-enamel junction; $\mathrm{HAB}$, height of alveolar bone.

dental-derived MSCs including PDLSCs and DPSCs. As to BMMSCs, SCAPs had similar potential in osteo/dentinogenic differentiation but higher proliferation rate, and they are easier to isolated [20]. In comparison with PDLSCs and DPSCs, SCAPs are superior with their MSCs capacity on population doubling rate and differentiation ability [24, 26]. Otherwise, SCAPs have been confirmed to have the ability to suppress the immune reaction through suppressing $\mathrm{T}$ cell proliferation which may help broaden the use of allogenic SCAPs transplantation by decreasing the immunoreaction [34]. With the discovery of key factors that maintain the function of SCAPs [35], strategies such as gene modification and the combined use of growth factor may be provided as effective attempts, while further investigation of the detailed mechanism about how SCAPs mediate periodontal tissue regenerative in periodontitis model still needs to be done.

\section{Conclusion}

Our data demonstrated that local injection of SCAPs can enhance the regeneration of periodontal tissue, which may serve as a promising therapy for periodontal tissue regeneration in the future.

\section{Data Availability}

The data used to support the findings of this study are included within the article.

\section{Conflicts of Interest}

The authors declare that there are no potential conflicts of interest. 


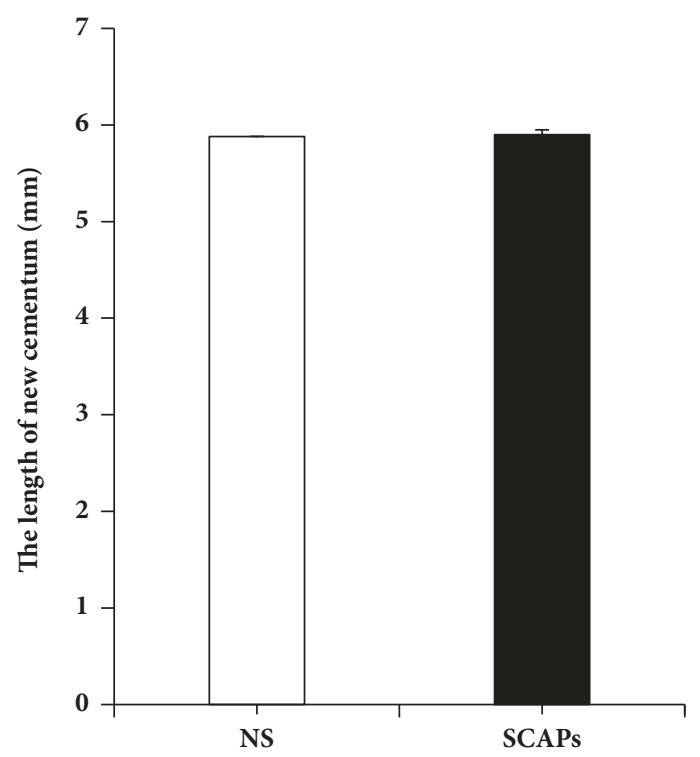

(a)

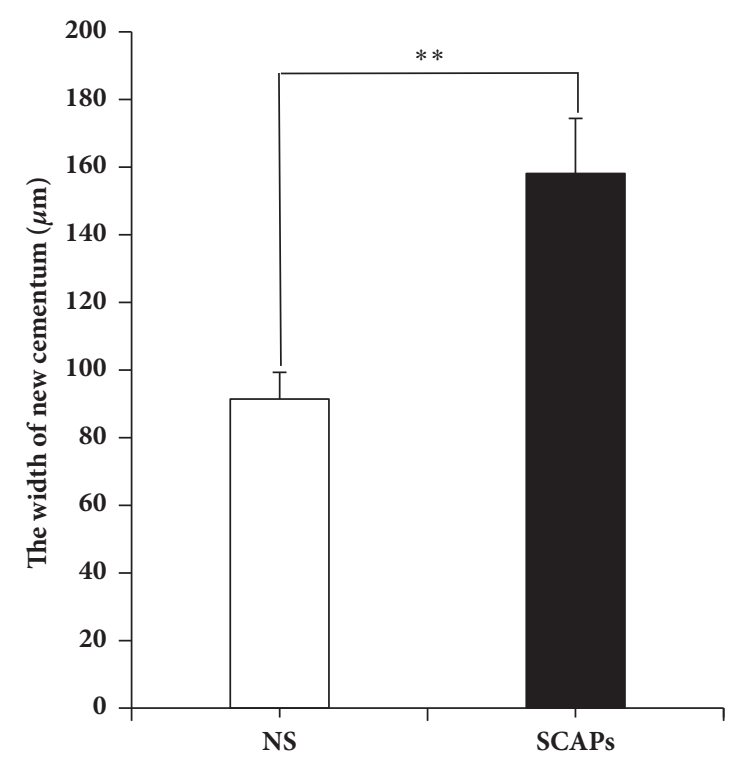

(b)

FIGURE 5: Quantitative analysis of new cementum showed more regeneration of new cementum in SCAPs group. (a, b) Quantitative analysis of HE staining showing new cementum regenerated in SCAPs group compared with $0.9 \% \mathrm{NaCl}$ group. Student's $t$-test was performed to determine statistical significance. Error bars represent $\mathrm{SD}(\mathrm{n}=6) . * * \mathrm{p} \leq 0.01$

\section{Acknowledgments}

This work was supported by grants from the National Natural Science Foundation of China (81625005 to ZPF), Beijing Natural Science Foundation (7172089 to ZPF), and Beijing Scholar Program (PXM2016_014226_000034, PXM2016_ 014226_000006, PXM2015_014226_000116, PXM2015_014226_ 000055, and PXM2015_014226_000052).

\section{Supplementary Materials}

Supplementary material contains computed tomography imaging of buccal lingual view in $0.9 \% \mathrm{NaCl}$ group and SCAPs group (Supplementary Figure 1). (Supplementary Materials)

\section{References}

[1] S. Rathod, T. Shori, T. Sarda, A. Raj, and P. Jadhav, "Comparative analysis of salivary sialic acid levels in patients with chronic obstructive pulmonary disease and chronic periodontitis patients: A biochemical study," Indian Journal of Dental Research, vol. 29, no. 1, p. 22, 2018.

[2] W. S. Borgnakke, P. V. Ylöstalo, G. W. Taylor, and R. J. Genco, "Effect of periodontal disease on diabetes: systematic review of epidemiologic observational evidence," Journal of Clinical Periodontology, vol. 40, no. s14, pp. S135-S152, 2013.

[3] Z. Cheng, J. Meade, K. Mankia, P. Emery, and D. A. Devine, "Periodontal disease and periodontal bacteria as triggers for rheumatoid arthritis," Best Practice \& Research Clinical Rheumatology, vol. 31, no. 1, pp. 19-30, 2017.

[4] B. L. Pihlstrom, B. S. Michalowicz, and N. W. Johnson, "Periodontal diseases," The Lancet, vol. 366, no. 9499, pp. 1809-1820, 2005.
[5] E. Ioannidou, Y. Hall, H. Swede, and J. Himmelfarb, "Periodontitis associated with chronic kidney disease among Mexican Americans," Journal of Public Health Dentistry, vol. 73, no. 2, pp. 112-119, 2013

[6] T. Rakmanee, G. S. Griffiths, G. Auplish et al., "Treatment of intrabony defects with guided tissue regeneration in aggressive periodontitis: clinical outcomes at 6 and 12 months," Clinical Oral Investigations, vol. 20, no. 6, pp. 1217-1225, 2016.

[7] W. V. Giannobile, "Treatment of periodontitis: Destroyed periodontal tissues can be regenerated under certain conditions," Journal of Periodontology, vol. 85, no. 9, pp. 1151-1154, 2014.

[8] J. Du, Z. Shan, P. Ma, S. Wang, and Z. Fan, "Allogeneic bone marrow mesenchymal stem cell transplantation for periodontal regeneration," Journal of Dental Research, vol. 93, no. 2, pp. 183$188,2014$.

[9] K. Hynes, D. Menicanin, J. Han et al., "Mesenchymal stem cells from iPS cells facilitate periodontal regeneration," Journal of Dental Research, vol. 92, no. 9, pp. 833-839, 2013.

[10] D. Akita, M. Morokuma, Y. Saito et al., "Periodontal tissue regeneration by transplantation of rat adipose-derived stromal cells in combination with PLGA-based solid scaffolds," Journal of Biomedical Research, vol. 35, no. 2, pp. 91-103, 2014.

[11] S. H. Bassir, W. Wisitrasameewong, J. Raanan et al., "Potential for stem cell-based periodontal therapy," Journal of Cellular Physiology, vol. 231, no. 1, pp. 50-61, 2016.

[12] L. Hu, Y. Liu, and S. Wang, "Stem cell-based tooth and periodontal regeneration," Oral Diseases, vol. 24, no. 5, pp. 696-705, 2018.

[13] D. Sadeghi, H. Nazarian, and H. Nojehdehian, "Adipose-derived stem cells combined with beta-tricalcium phosphate: A novel possible strategy for periodontal defects regeneration," Medical Hypotheses, vol. 82, no. 1, pp. 54-56, 2014.

[14] K. M. Fawzy El-Sayed, C. Dörfer, F. Fändrich, F. Gieseler, M. H. Moustafa, and H. Ungefroren, "Adult mesenchymal stem 
cells explored in the dental field," Advances in Biochemical Engineering/Biotechnology, vol. 130, pp. 89-103, 2013.

[15] X. Fu, L. Jin, P. Ma, Z. Fan, and S. Wang, "Allogeneic stem cells from deciduous teeth in treatment for periodontitis in Miniature Swine," Journal of Periodontology, vol. 85, no. 6, pp. 845-851, 2014.

[16] Y. Liu, Y. Zheng, G. Ding et al., "Periodontal ligament stem cellmediated treatment for periodontitis in miniature swine," Stem Cells, vol. 26, no. 4, pp. 1065-1073, 2008.

[17] J. Hu, Y. Cao, Y. Xie et al., "Periodontal regeneration in swine after cell injection and cell sheet transplantation of human dental pulp stem cells following good manufacturing practice," Stem Cell Research \& Therapy, vol. 7, no. 1, article no. 130, 2016.

[18] D. Ponnaiyan, K. M. Bhat, and G. S. Bhat, "Comparison of immuno-phenotypes of stem cells from human dental pulp and periodontal ligament," International Journal of Immunopathology and Pharmacology, vol. 25, no. 1, pp. 127-134, 2012.

[19] S. S. Hakki, S. A. Kayis, E. E. Hakki et al., "Comparison of mesenchymal stem cells isolated from pulp and periodontal ligament," Journal of Periodontology, vol. 86, no. 2, pp. 283-291, 2015.

[20] K. M. Galler, A. C. Cavender, U. Koeklue, L. J. Suggs, G. Schmalz, and R. N. D'Souza, "Bioengineering of dental stem cells in a PEGylated fibrin gel," Journal of Regenerative Medicine, vol. 6, no. 2, pp. 191-200, 2011.

[21] A. R. Navabazam, N. F. Sadeghian, M. H. Sheikhha, S. M. Miresmaeili, M. Soleimani, and F. Fesahat, "Characterization of mesenchymal stem cells from human dental pulp, preapical follicle and periodontal ligament," Iranian Journal of Reproductive Medicine, vol. 11, no. 3, pp. 235-242, 2013.

[22] S. Cantore, A. Ballini, D. De Vito et al., "Characterization of human apical papilla-derived stem cells," Journal of Biological Regulators \& Homeostatic Agents, vol. 31, no. 4, pp. 901-910, 2017.

[23] W. Sonoyama, Y. Liu, T. Yamaza et al., "Characterization of the apical papilla and its residing stem cells from human immature permanent teeth: a pilot study," Journal of Endodontics, vol. 34, no. 2, pp. 166-171, 2008.

[24] K. Chen, H. Xiong, Y. Huang, and C. Liu, "Comparative analysis of in vitro periodontal characteristics of stem cells from apical papilla (SCAP) and periodontal ligament stem cells (PDLSCs)," Archives of Oral Biolog, vol. 58, no. 8, pp. 997-1006, 2013.

[25] W. Sonoyama, Y. Liu, D. Fang et al., "Mesenchymal stem cellmediated functional tooth regeneration in Swine," PLOS ONE, vol. 1, no. 1, article e79, 2006.

[26] A. Bakopoulou, G. Leyhausen, J. Volk et al., "Comparative analysis of in vitro osteo/odontogenic differentiation potential of human dental pulp stem cells (DPSCs) and stem cells from the apical papilla (SCAP)," Archives of Oral Biolog, vol. 56, no. 7, pp. 709-721, 2011.

[27] D. Tziafas and K. Kodonas, "Differentiation Potential of Dental Papilla, Dental Pulp, and Apical Papilla Progenitor Cells," Journal of Endodontics, vol. 36, no. 5, pp. 781-789, 2010.

[28] C. Morsczeck, G. Schmalz, T. E. Reichert, F. Völlner, K. Galler, and O. Driemel, "Somatic stem cells for regenerative dentistry," Clinical Oral Investigations, vol. 12, no. 2, pp. 113-118, 2008.

[29] Y. Cao, D. S. Xia, S. R. Qi et al., "Epiregulin can promote proliferation of stem cells from the dental apical papilla via MEK/Erk and JNK signalling pathways," Cell Proliferation, vol. 46, no. 4, pp. 447-456, 2013.
[30] G. Yu, J. Wang, X. Lin et al., "Demethylation of SFRP2 by histone demethylase KDM2A regulated osteo-/dentinogenic differentiation of stem cells of the apical papilla," Cell Proliferation, vol. 49, no. 3, pp. 330-340, 2016.

[31] G. Ding, Y. Liu, W. Wang et al., "Allogeneic periodontal ligament stem cell therapy for periodontitis in swine," Stem Cells, vol. 28, no. 10, pp. 1829-1838, 2010.

[32] P. Hilkens, A. Bronckaers, J. Ratajczak, P. Gervois, E. Wolfs, and I. Lambrichts, "The angiogenic potential of DPSCs and SCAPs in an in vivo model of dental pulp regeneration," Stem Cells International, vol. 2017, 2017.

[33] N. B. Ruparel, J. F. A. De Almeida, M. A. Henry, and A. Diogenes, "Characterization of a stem cell of apical papilla cell line: Effect of passage on cellular phenotype," Journal of Endodontics, vol. 39, no. 3, pp. 357-363, 2013.

[34] J. Liu, F. Yu, Y. Sun et al., "Concise reviews: characteristics and potential applications of human dental tissue-derived mesenchymal stem cells," Stem Cells, vol. 33, no. 3, pp. 627-638, 2014.

[35] S. Diao, X. Lin, L. Wang et al., "Analysis of gene expression profiles between apical papilla tissues, stem cells from apical papilla and cell sheet to identify the key modulators in MSCs niche," Cell Proliferation, vol. 50, no. 3, Article ID e12337, 2017. 


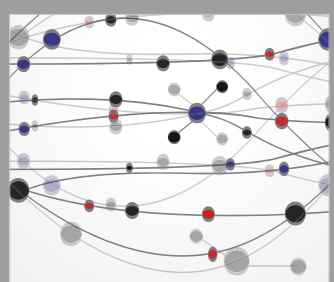

The Scientific World Journal
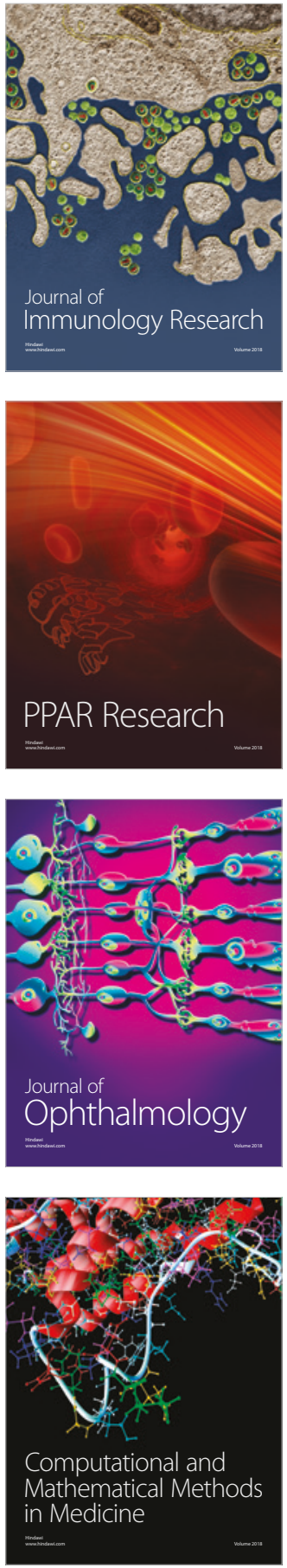

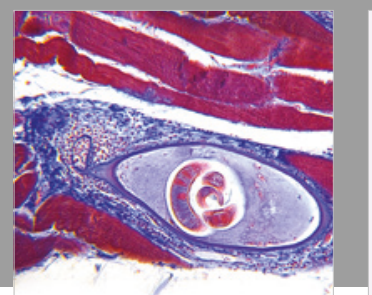

Gastroenterology Research and Practice

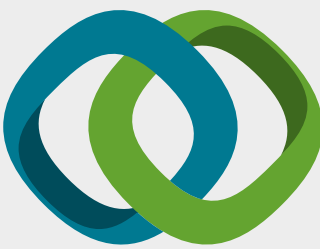

\section{Hindawi}

Submit your manuscripts at

www.hindawi.com
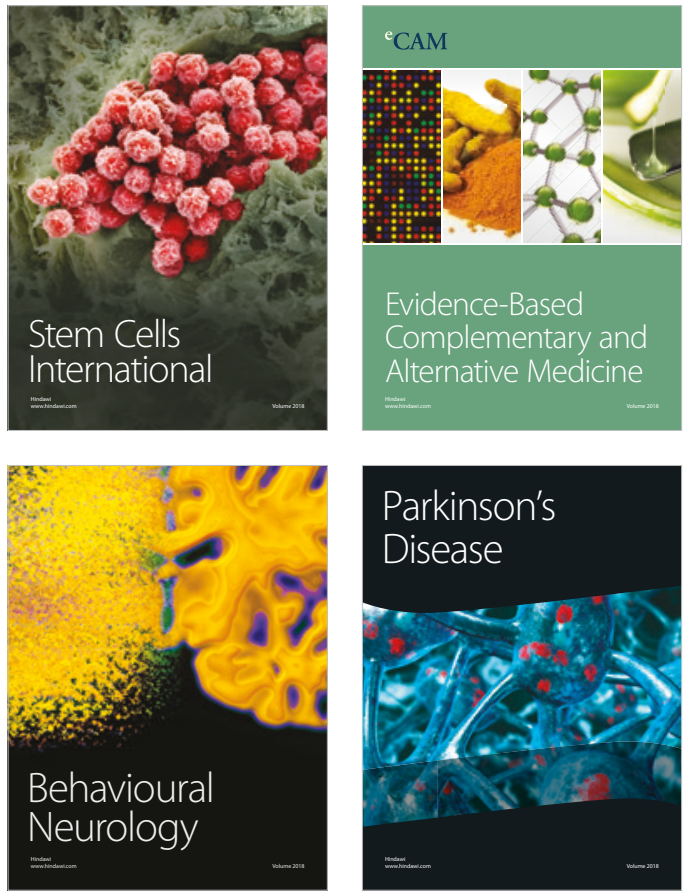

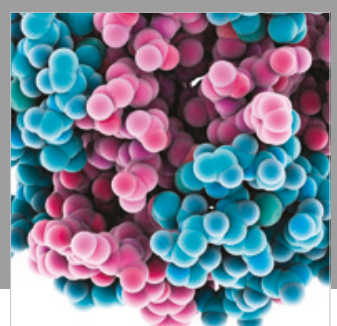

ournal of

Diabetes Research

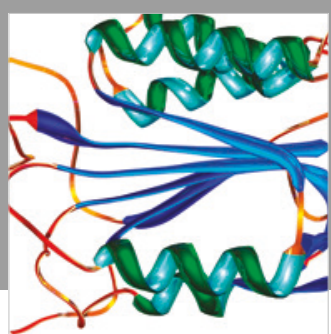

Disease Markers
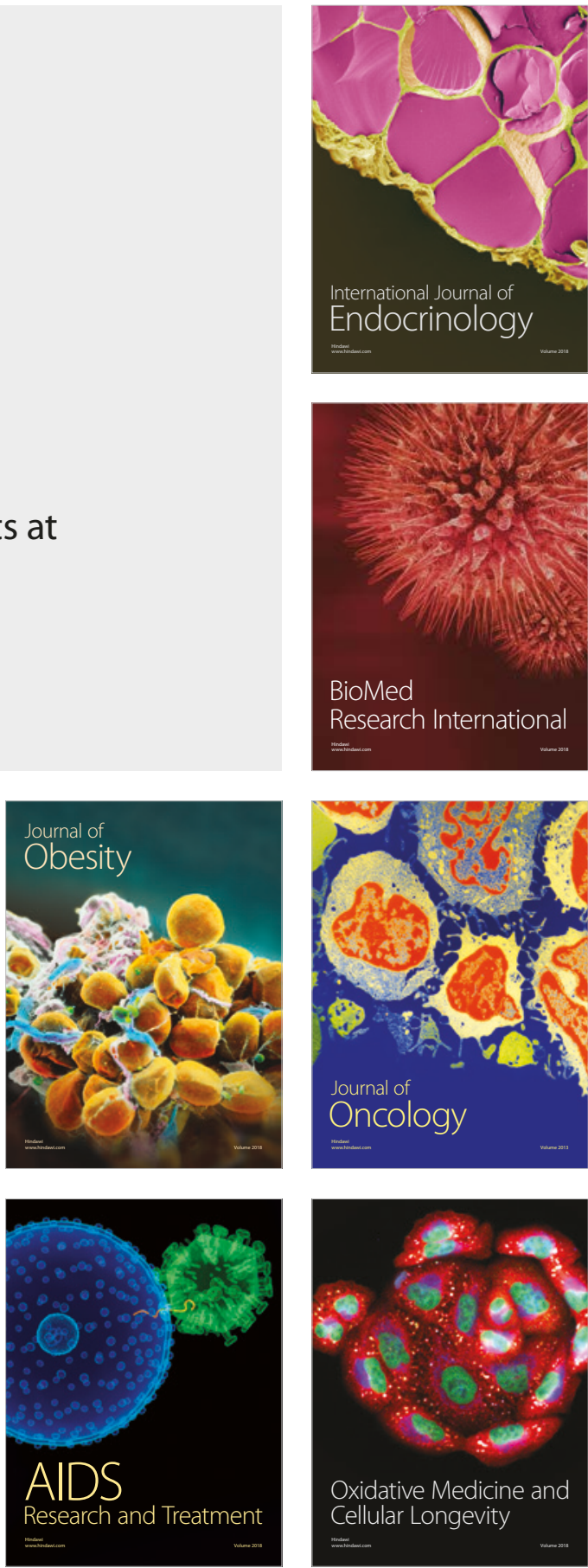